\title{
Analytical study on irradiated methylxanthine derivatives
}

\author{
Barbara Marciniec • Maciej Stawny • \\ Karol Olszewski $\cdot$ Maciej Kozak $\cdot$ Marek Naskrent
}

Received: 8 April 2012/Accepted: 12 October 2012/Published online: 9 November 2012

(C) The Author(s) 2012. This article is published with open access at Springerlink.com

\begin{abstract}
The effect of ionising radiation on the physicochemical properties of three derivatives of xanthine: caffeine, theophylline and theobromine, has been studied. The above-drugs in the solid phase have been irradiated with E-beam of the energy $9.96 \mathrm{MeV}$ with the doses varied from 25 to $400 \mathrm{kGy}$. The effects of the irradiation have been examined by differential scanning calorimetry (DSC), electron paramagnetic resonance (EPR) and high-performance liquid chromatography (HPLC). The results have shown that the methylxanthine derivatives studied are resistant to ionising irradiation in the doses usually used for sterilisation $(<50 \mathrm{kGy})$, which means that they are relatively radiochemically stable and can be sterilised by irradiation.
\end{abstract}

Keywords Radiation sterilization - Caffeine · Theophylline Theobromine

B. Marciniec $(\square) \cdot$ M. Stawny $\cdot$ K. Olszewski

Department of Pharmaceutical Chemistry, Karol Marcinkowski University of Medical Sciences, 6 Grunwaldzka Street, 60-780 Poznań, Poland

e-mail: bmarcin@ump.edu.pl

M. Kozak

Department of Macromolecular Physics, Faculty of Physics, Adam Mickiewicz University, 85 Umultowska Street,

61-614 Poznań, Poland

M. Naskrent

Department of Medical Physics, Faculty of Physics, Adam Mickiewicz University, 85 Umultowska Street, 61-614 Poznań, Poland

\section{Introduction}

Radiation sterilisation has been successfully used in the food, cosmetic and pharmaceutical industry [1]. The need for testing the radiochemical stability of medical therapy drugs follows from the possible application of the bactericidal effect of ionising radiation in the process of their sterilisation in the solid state [2, 3] in drug formulation [3] and in water solutions [4]. The mechanism of bactericidal effect of ionising radiation can be either direct (damage to cell macromolecules) or indirect (water radiolysis) and the final effect is inhibition of living functions of bacteria and their endospores $[1,5]$. Unfortunately, ionising radiation besides the bactericidal effect can change the active substance of the drug which may lead to the loss of pharmacological activity or even the appearance of harmful effect [2]. The irradiation caused changes most often observed in drugs include the formation of free radicals and products of decomposition, discolouration, changes in the crystal lattice and/or crystal structure [6]. For the above-reasons it is necessary to determine the radiochemical stability of therapeutic drugs and check the possibility of their sterilisation by irradiation.

The aim of this study was determination of the radiochemical stability of three derivatives of methylxanthine (caffeine, theophilline and theobromine) in solid phase. The drugs are used in medical treatment often in the form of injections so they must be sterile.

The three derivatives of methylxanthine in solid phase were irradiated with ionising radiation produced by a beam of electrons of energy $9.96 \mathrm{MeV}$ in the doses of 25,50 , 100,200 and $400 \mathrm{kGy}$, and then subjected to analytical examination. According to the European Norm EN 552 [7], the dose recommended for radiation sterilisation is $25 \mathrm{kGy}$, but the use of higher doses in our experiment followed 
from the fact that after irradiation with higher doses the possible changes are more pronounced and the content of the radiolysis products is increased so easier to detect. To check if the three derivatives of methylxanthine could be safely sterilised by irradiation, the drugs non-irradiated and irradiated with different doses were subjected to examination by HPLC, EPR and DSC methods.

\section{Materials and methods}

Materials

Characterisations of the investigated caffeine $\mathrm{CF}$ (serial number 014K0036, content $101.2 \%$ ), theophylline TP (serial number 192077, content $99.91 \%$ ) and theobromine TB (serial number 055K2519, content $99.94 \%$ ) are presented in Table 1. All investigated substances were in the form of white, loose powder and obtained from SigmaAldrich.

\section{Exposure to irradiation}

Approximately $1.0 \mathrm{~g}$ of $\mathrm{TB}$ and $\mathrm{TP}$ and $0.5 \mathrm{~g}$ of $\mathrm{CF}$ was placed in a colourless glass vial of $5 \mathrm{ml}$ in capacity and closed with a plastic stopper. The samples in the vials were exposed to irradiation in a linear electron accelerator LAE $13 / 9$ (electron beam $9.96 \mathrm{MeV}$ and current intensity $6.2 \mu \mathrm{A})$ till they had absorbed a dose of 25, 50, 100, 200 and $400 \mathrm{kGy}$.

Table 1 Chemical properties of methylxanthine derivatives [8]

\begin{tabular}{|c|c|c|c|}
\hline $\begin{array}{l}\text { Chemical } \\
\text { name }\end{array}$ & $\begin{array}{l}\mathrm{CF} \\
\text { 3,7-Dihydro-1,3,7- } \\
\text { trimthyl-1H- } \\
\text { purine-2,6-dione }\end{array}$ & $\begin{array}{l}\text { TP } \\
\text { 3,7-Dihydro- } \\
\text { 1,3-dimthyl-1H- } \\
\text { purine-2,6- } \\
\text { dione }\end{array}$ & $\begin{array}{l}\text { TB } \\
\text { 3,7-Dihydro- } \\
\text { 3,7-dimthyl-1H- } \\
\text { purine-2,6- } \\
\text { dione }\end{array}$ \\
\hline \multirow[t]{2}{*}{$\begin{array}{l}\text { Chemical } \\
\text { structure }\end{array}$} & & & \\
\hline & $\mathrm{R}_{1}=\mathrm{R}_{2}=\mathrm{R}_{3}=\mathrm{CH}_{3}$ & $\begin{array}{l}\mathrm{R}_{1}=\mathrm{R}_{3}=\mathrm{CH}_{3} \\
\mathrm{R}_{2}=\mathrm{H}\end{array}$ & $\begin{array}{l}\mathrm{R}_{2}=\mathrm{R}_{3}=\mathrm{CH}_{3} \\
\mathrm{R}_{1}=\mathrm{H}\end{array}$ \\
\hline $\begin{array}{c}\text { Molecular } \\
\text { formula }\end{array}$ & $\mathrm{C}_{8} \mathrm{H}_{10} \mathrm{~N}_{4} \mathrm{O}_{2}$ & $\mathrm{C}_{7} \mathrm{H}_{8} \mathrm{~N}_{4} \mathrm{O}_{2}$ & $\mathrm{C}_{7} \mathrm{H}_{8} \mathrm{~N}_{4} \mathrm{O}_{2}$ \\
\hline $\begin{array}{l}\text { Molecular } \\
\text { mass/g } \\
\mathrm{mol}^{-1}\end{array}$ & 194.2 & 180.2 & 180.2 \\
\hline $\begin{array}{l}\text { Melting } \\
\text { point } /{ }^{\circ} \mathrm{C}\end{array}$ & 178 & $270-274$ & 290-295 \\
\hline
\end{tabular}

Table 2 Results of HPLC analysis of the methylxanthines studied

\begin{tabular}{lccc}
\hline Dose/kGy & \multicolumn{2}{l}{ Content/\% } \\
\cline { 2 - 4 } & CF & TP & TB \\
\hline 0 & 100.0 & 100.0 & 100.0 \\
25 & 99.56 & 99.90 & 98.80 \\
50 & 99.64 & 99.16 & 98.76 \\
100 & 99.48 & 99.05 & 98.55 \\
200 & 98.95 & 98.98 & 97.97 \\
400 & 98.87 & 98.80 & 97.42 \\
\hline
\end{tabular}

Differential scanning calorimetry (DSC)

Measurements were performed on an apparatus DSC-204 made by Netzsch. Samples of $3 \mathrm{mg}$ were closed in aluminium crucibles with pierced lids. Before measurements, the samples were thermally equilibrated at $20{ }^{\circ} \mathrm{C}$ for $5 \mathrm{~min}$, and the measurements were performed at the heating rate of $5{ }^{\circ} \mathrm{C} \mathrm{min}{ }^{-1}$, in helium atmosphere $\left(40 \mathrm{~mL} \mathrm{~min}^{-1}\right)$. For each sample, three independent measurements were performed and the results were averaged. The data were analyzed using TA Netzsch programme. For determination of enthalpy values characterizing phase transitions, a linear or a tangentsigmoidal baseline was used.

High-performance liquid chromatography (HPLC)

The HPLC system consisted of a Waters Model 616 solvent pump system equipped with a Photodiode Array UV-Vis Waters 996 detector set at $272 \mathrm{~nm}$ for TF and $273 \mathrm{~nm}$ for CF and TB. Chromatographic separation was performed with a Xterra $\mathrm{C} 18$ reverse phase column $(3.9 \times 150 \mathrm{~mm}, 2.5 \mu \mathrm{m}$ particle size $)$, and the mobile phase was phosphate buffer-acetonitrile $80: 20 \mathrm{v} / \mathrm{v}$ at a flow

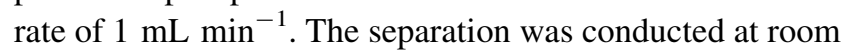
temperature.

\section{Electron paramagnetic resonance (EPR)}

The EPR experiments were carried out for all non-irradiated, irradiated samples, in standard EPR quartz sample tubes from Wilmad. The measurements were performed with a Bruker EPR EMX-10 spectrometer working at $9.4 \mathrm{GHz}$ (X-band) at room temperature $(293 \mathrm{~K})$. The sensitivity of the spectrometer was $1 \times 10^{10}$ spins $\mathrm{g}^{-1}$. Induction of the magnetic field was measured to the accuracy of $0.001 \mathrm{mT}$. Microwave frequency was measured to the accuracy of $0.001 \mathrm{GHz}$. The spectra were double integrated over the magnetic field range 334-354 mT, which gives a figure proportional to the number of radicals in the sample. 


\section{Results and discussion}

An interesting observation was that the methylxanthine derivatives studied did not change the colours upon irradiation with ionising radiation produced by a beam of electrons of energy $9.96 \mathrm{MeV}$, in the doses of 25, 50, 100, 200 and $400 \mathrm{kGy}$. It is unusual as very often ionising radiation causes change in colour. The change in colour is explained by the formation of colour products of decomposition (absorbing light in visual range and giving colour solutions) or by a damage to the crystal lattice and formation of the so-called colour centres or F centres also absorbing light in visual range. The $\mathrm{F}$ centres are made by anion voids with an electron captured inside. Formation of more complex electron trapping centres is possible made of a few $\mathrm{F}$ centres. As the crystal must remain neutral, the formation of colour centres is accompanied by the formation of hole centres known also as V centres [9].

The lack of change in colour in the methylxanthine derivatives studied upon irradiation with a dose of $400 \mathrm{kGy}$, so 16-times higher than the standard sterilisation dose, suggested that these compounds must be exceptionally resistant to ionising radiation. Changes in colour (from white to light yellow) upon irradiation with $25 \mathrm{kGy}$ have been observed for pilocarpine hydrochloride [10]. Also a change in colour upon irradiation has been observed for chloramphenicol sodium succinate, but for this compound it was accompanied by granulation and a change in the degree of crystallinity [11].

As no change in colour was observed upon irradiation of methylxanthine derivatives studied, to detect possible products of decomposition of these compound the HPLC method was applied (Fig. 1). Table 2 presents the contents of the active substance (methylxanthine derivatives) in the samples subjected to irradiation determined by HPLC. For $\mathrm{CF}$ and TF irradiated with doses from 25 to $100 \mathrm{kGy}$, the loss in content was less than $1 \%$, while upon irradiation with 200 and $400 \mathrm{kGy}$, the loss in content did not exceed $1.20 \%$. For TB, the loss in content upon irradiation with $25 \mathrm{kGy}$ was $1.20 \%$ and increased to $2.58 \%$ upon irradiation with $400 \mathrm{kGy}$.

In comparison to the loss in content upon irradiation observed for other drugs $[6,11]$ the loss in content for the methylxanthine derivatives was exceptionally small, which means that their radiodegradation was indeed not much, even after irradiation with $400 \mathrm{kGy}$. For many drugs subjected to ionising radiation the dose-dependent losses in content have been observed reaching even a few $10 \%[6,11]$.

The very small changes in the content upon irradiation of the methylxanthine derivatives studied were probably a consequence of their simple chemical structure making a compact system of two rings and the lack of longer or branched substituents.

Besides HPLC measurements, the methylxanthine derivatives were also subjected to DSC analyses. The DSC method is very useful for quick assessment of radiochemical stability of drugs in solid state. This application of DSC is based on the van Hoff equation indicating that the melting point of a compound containing impurities (i.e. all other chemical compounds besides the active substance, including the products of the active substance radiodegradation) is always lower than that of the pure compound. Thus, for the drugs of low-radiochemical stability and easily undergoing radiodegradation the DSC peak
Fig. 1 HPLC chromatograms of methylxanthine derivatives before and after irradiation with the dose of $400 \mathrm{kGy}$
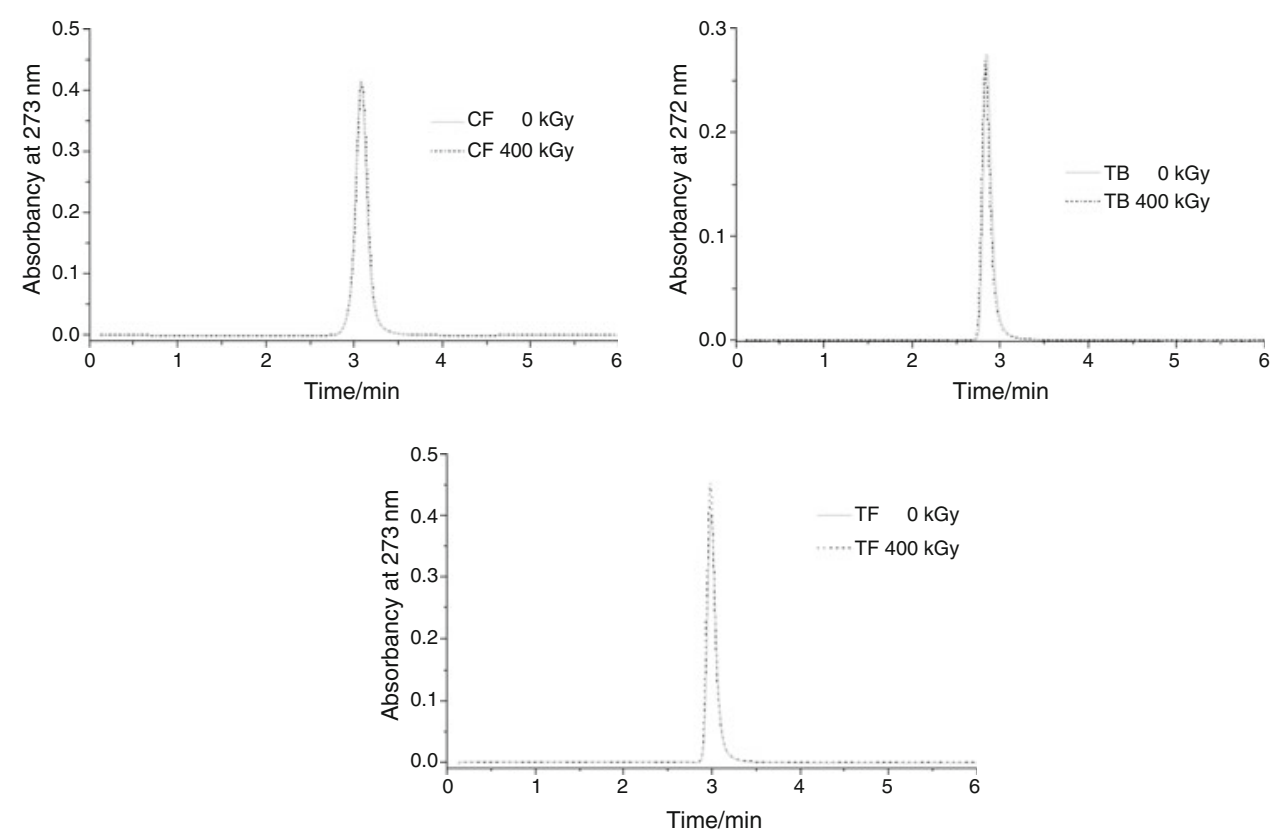
Fig. 2 DSC curves recorded for the methylxanthines studied prior to and after irradiation
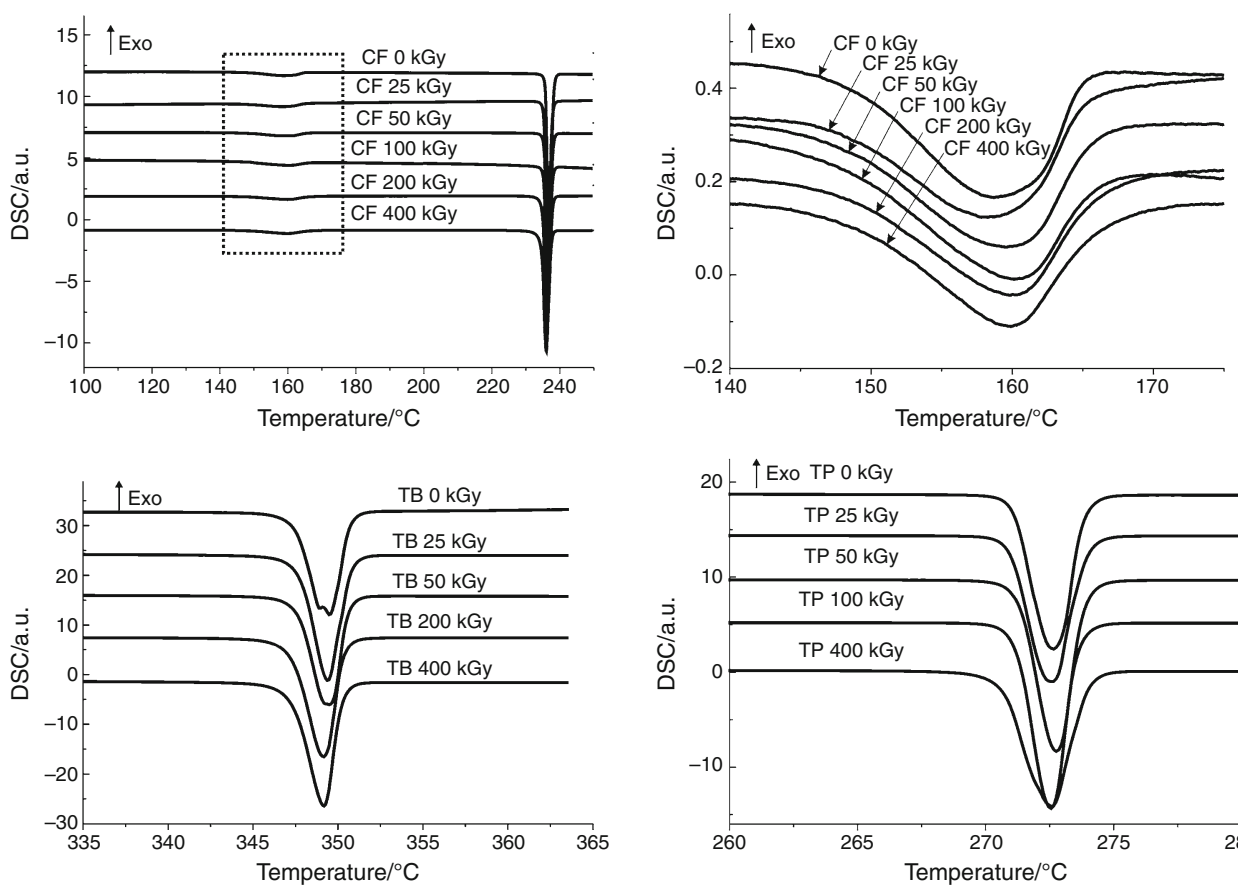

Table 3 Results of DSC analysis of the methylxanthines studied

\begin{tabular}{|c|c|c|c|c|c|c|c|}
\hline Związek badany & Dawka/kGy & $T_{\text {onset }} /{ }^{\circ} \mathrm{C}$ & $T_{\text {peak }} /{ }^{\circ} \mathrm{C}$ & $\Delta H / \mathrm{J} \mathrm{g}^{-1}$ & $T_{\text {onset }}-T_{\text {onset } 0 / \mathrm{kGy}} /{ }^{\circ} \mathrm{C}$ & $T_{\text {peak }}-T_{\text {peak } 0 / \mathrm{kGy}} /{ }^{\circ} \mathrm{C}$ & $\Delta H-\Delta H_{0 / \mathrm{kGy}} / \mathrm{J} \mathrm{g}^{-1}$ \\
\hline \multirow[t]{6}{*}{$\mathrm{CF}$} & 0 & 235.7 & 236.8 & 117.2 & & & \\
\hline & 25 & 235.4 & 236.4 & 113.4 & -0.3 & -0.4 & -3.8 \\
\hline & 50 & 235.5 & 236.5 & 113.0 & -0.2 & -0.3 & -4.2 \\
\hline & 100 & 235.4 & 236.4 & 109.6 & -0.3 & -0.4 & -7.6 \\
\hline & 200 & 235.0 & 236.2 & 109.9 & -0.7 & -0.6 & -7.3 \\
\hline & 400 & 234.7 & 236.0 & 108.6 & -1.0 & -0.8 & -8.6 \\
\hline \multirow[t]{6}{*}{ TP } & 0 & 271.0 & 272.6 & 183.4 & & & \\
\hline & 25 & 270.9 & 272.6 & 182.7 & -0.1 & 0.0 & -0.7 \\
\hline & 50 & 270.9 & 272.6 & 179.1 & -0.1 & 0.0 & -4.3 \\
\hline & 100 & 270.8 & 272.6 & 176.0 & -0.2 & 0.0 & -7.4 \\
\hline & 200 & 270.7 & 272.4 & 175.0 & -0.3 & -0.2 & -8.4 \\
\hline & 400 & 270.6 & 272.3 & 173.5 & -0.4 & -0.3 & -9.9 \\
\hline \multirow[t]{6}{*}{ TB } & 0 & 347.4 & 349.5 & 299.7 & & & \\
\hline & 25 & 347.4 & 349.5 & 299.3 & 0.0 & 0.0 & -0.4 \\
\hline & 50 & 347.4 & 349.4 & 299.1 & 0.0 & -0.1 & -0.6 \\
\hline & 100 & 347.4 & 349.1 & 298.8 & 0.0 & -0.4 & -0.9 \\
\hline & 200 & 347.3 & 349.2 & 296.0 & -0.1 & -0.3 & -3.7 \\
\hline & 400 & 347.3 & 349.2 & 290.3 & -0.1 & -0.3 & -9.4 \\
\hline
\end{tabular}

corresponding to melting is shifted towards lower temperatures, which is related to the presence of the products of degradation. The usefulness of DSC for this purpose has been tested many times for some groups of drugs, e.g. betalactam antibiotics, derivatives of azole, imidazole, phenylpropanol, sulphonamides, certain alkaloids and others [10-18].
For the methylxanthine derivatives studied, no changes in the character of DSC curves were observed upon their irradiation that could testify to the presence of radiolysis products or changes in the physicochemical properties of the compounds studied (Fig. 2). For TP and TB one endothermic peak was observed near the melting point of the relevant compounds (at $\sim 272{ }^{\circ} \mathrm{C}$ for $\mathrm{TP}$ and at 
Fig. 3 EPR spectra of methylxanthine derivatives before and immediately after irradiation with the dose of $25 \mathrm{kGy}$
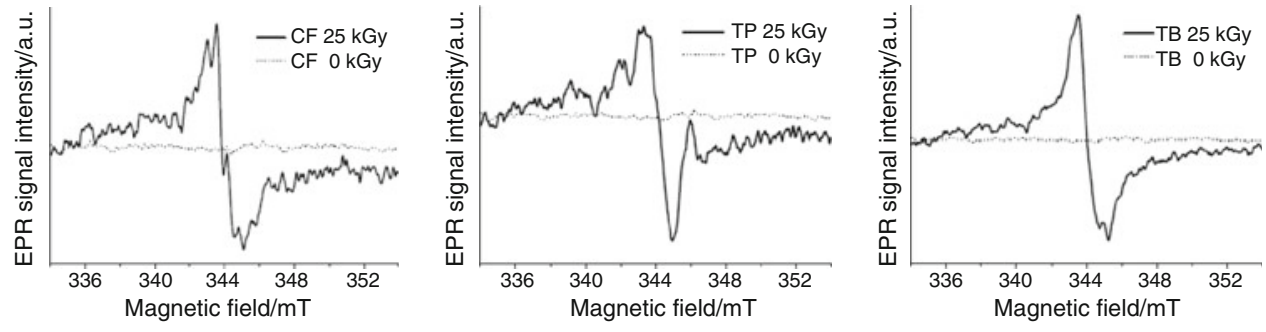

Table 4 Changes in the melting points of some groups of drugs upon ionising radiation produced by E-beam

\begin{tabular}{lrrl}
\hline Group of drugs & \multicolumn{2}{l}{$\begin{array}{l}\text { Decrease of melting } \\
\text { point/ }{ }^{\circ} \mathrm{C}\end{array}$} & References \\
\cline { 2 - 3 } & $25 \mathrm{kGy}$ & $200 \mathrm{kGy}$ & \\
\hline Methylxanthines & $0-0.3$ & $0.1-0.7$ & - \\
Sulphonamides & $0-1.1$ & $2.3-5.7$ & {$[16]$} \\
Imidazoline derivatives & $0.1-0.4$ & $0.2-1.4$ & {$[15]$} \\
Azole derivatives & $0.3-0.7$ & $0.7-2.9$ & {$[13,14]$} \\
Alkaloids & $0.3-3.9$ & $0.3-6.9$ & {$[10]$} \\
1.4-Dihydropyridine derivatives & $0.5-2.2$ & $1.0-2.9$ & {$[21]$} \\
\hline
\end{tabular}

$\sim 349{ }^{\circ} \mathrm{C}$ for $\left.\mathrm{TB}\right)$. For $\mathrm{CF}$ besides the solid $\rightarrow$ liquid $\left(\sim 236{ }^{\circ} \mathrm{C}\right)$ phase transition also a change in the polymorphic form was noted at about $160{ }^{\circ} \mathrm{C}$. According to the literature on thermal investigation of methylxanthine derivatives [19], the course of their DSC curves is characteristic of anhydrous forms and the curve recorded for $\mathrm{CF}$ also implies that this derivative occurs in the polymorphic form $\alpha \mathrm{CF}$ (form II), while the peak appearing at $\sim 160{ }^{\circ} \mathrm{C}$ corresponds to the transition of $\mathrm{CF}$ into a new polymorphic form (form I).

As a result of irradiation the character of the DSC curves recorded did not change and only slight changes in the values of $T_{\text {peak }}$ and $T_{\text {onset }}$ were noted (Table 3 ). The most pronounced differences in these temperatures before and after irradiation were detected for $\mathrm{CF}$ irradiated with a dose of $400 \mathrm{kGy}, \Delta T_{\text {onset }}=-1.0{ }^{\circ} \mathrm{C}$ and $\Delta T_{\text {peak }}=-0.8{ }^{\circ} \mathrm{C}$. Similarly as the lack of colour changes and HPLC results, these small changes in $T_{\text {onset }}$ and $T_{\text {peak }}$ implied highradiochemical stability of the three compounds studied.

As ionising radiation results first of all in emission of electrons as a consequence of the photoelectric phenomenon and Compton effect leading to free radicals generation, the above-compounds studied were subjected to qualitative and quantitative EPR analysis. The generation of free radicals is on the one hand responsible for damage to biological structures of micro-organisms and is one of the main bactericidal mechanisms involved in radiation sterilisation, but on the other hand ionising radiation generates free radicals also in the therapeutic drug. If this happens the free radicals initiate degradation of the drug and can lead to a number of undesirable effects.

In non-irradiated derivatives of methylxanthine studied no presence of free radicals was detected, and after the irradiation with a dose of $25 \mathrm{kGy}$ their EPR spectra were characterised by low intensity (Fig. 3). The EPR spectrum of $\mathrm{CF}$ revealed a hyperfine structure, while the spectrum of TB was anisotropic. For CF, TP and TB the amounts of unpaired spins were $4.27 \times 10^{14}, 3.82 \times 10^{14}$ and $5.23 \times 10^{14}$ spin $\mathrm{g}^{-1}$, and the gyromagnetic coefficient (g factor) are 2.0029, 2.0043 and 2.0054, respectively.

\section{Conclusions}

As follows from the above-presented and discussed results, the methylxanthine derivatives studied in solid phase show relatively high-radiochemical stability upon irradiation with the doses applied. From among them CF and TP are a bit more resistant to the ionising radiation than $\mathrm{TB}$, for which the decrease in content after irradiation with $400 \mathrm{kGy}$ was $2.58 \%$ (HPLC), the decrease in content of $\mathrm{CF}$ and TP was within the error of the method.

Analysis of the chemical structure of the compounds studied suggests that the methyl substituent at $\mathrm{N}_{1}$ in $\mathrm{CF}$ and TP is responsible for their greater radiochemical stability than that of TB which has no substituent at this position. It is supposed that the presence of the substituent at $\mathrm{N}_{1}$ blocks the transformation of the molecule to the enol form, which may be an important protection against radiodegradation.

Against the background of the hitherto results concerning radiochemical stability of mediac therapy drugs, methylxanthines belong to the compounds exceptionally resistant to ionising radiation. Many drugs have shown a gamut of changes in the physical properties (change in colour, change in crystallisation degree and change in chirality) and chemical properties (oxidation, cleavage of chemical bonds, dehydrogenation, formation of free radicals) after irradiation with a minimum dose. The changes were often directional and intensified with increasing dose of irradiation [10, 13, 20-28]. For many irradiated drugs also a shift of the melting point was observed towards lower temperatures which was related to the appearance of 
the products of irradiation (Table 4). For some drugs linear relations were observed between the decrease in the melting point and increase in the irradiation dose as well as between the decrease in the melting point and decrease in content of the active substance.

The very small decrease in the melting point observed by DSC and small changes measured by other methods allow us to conclude that sterilisation by irradiation can by applied to these compounds. Methylxanthines are probably one of the therapeutic drugs most resistant to ionising radiation emitted by a beam of electrons.

Acknowledgements Authors wish to acknowledge to help of Dr E. Jaroszkiewicz, Department of Pharmacy and Pharmaceutical Sciences, De Montfort University, The Gateway, Leicester LE19 BH, $\mathrm{UK}$ in redaction process of this manuscript.

Open Access This article is distributed under the terms of the Creative Commons Attribution License which permits any use, distribution, and reproduction in any medium, provided the original author(s) and the source are credited.

\section{References}

1. Ražem D. Trends in radiation sterilization of health care products. Radiation sterilization of pharmaceuticals: an overview of the literature. Vienna: IAEA; 2008. p. 175-85.

2. Tilquin B. Radiation chemistry from basics to application in material and life sciences. Radiosterilization of drugs. France: EDP Sciences; 2008. p. 151-63.

3. Berk F, Ozer AY. Radiation sterilization I: radiosterilization of medical devices. J Pharm Sci. 1999;24:223-31.

4. Slegers C, Tilquin B. Final product analysis in the e-beam and gamma radiolysis of aqueous solutions of metoprolol tartrate. Radiat Phys Chem. 2006;75:1006-10.

5. Dam A, Gazso LG, Grigorova P. Microbiological investigation for radiation treatment of pharmaceuticals. Radiat Phys Chem. 1990;35:396-9.

6. Marciniec B, Dettlaff K. Trends in radiation sterilization of health care products. Radiation sterilization of drugs. Vienna: IAEA; 2008. p. 187-230.

7. CEN, EN 552. Sterilization of medical devices-validation and routine control of sterilization by irradiation. European Committee for Standardization, Rue de Strassart 36, B-1050, Belgium; 1994.

8. European pharmacopoeia, 5th ed. Council of Europe: Strasburg; 2002.

9. Wang SQ, Liu CP, Ye HQ. A Study on crystal defects in epitaxial $\mathrm{GaN}$ film by high-order weak-beam electron microscopy. Mater Character. 2000;44:385-9.
10. Marciniec B, Kozak M, Naskrent M, Hofman M, Dettlaff K, Stawny M. DSC and EPR analysis of some radiation sterilized alkaloids. J Therm Anal Calorim. 2010;102:261-7.

11. Marciniec B, Stawny M, Jaroszkiewicz E. Comparison of influence of gamma rays and e-beam on some chloramphenicol derivatives. Curr Anal Chem. 2012;8:337-43.

12. Marciniec B, Płotkowiak Z, Wachowski L, Kozak M, PopielarzBrzezińska M. Analytical study of $\beta$-irradiated antibiotics in the solid state. J Therm Anal. 2002;68:423-36.

13. Marciniec B, Dettlaff $K$, Naskrent M. Influence of ionizing irradiation on clotrimazole in the solid state. J Pharm Biomed Anal. 2009;50:675-8.

14. Marciniec B, Dettlaff K, Jaroszkiewicz E, Bafeltowska J. Radiochemical stability of fluconazole in the solid state. J Pharm Biomed Anal. 2007;43:1876-80.

15. Marciniec B, Kozak M, Naskrent M, Dettlaff K, Ogrodowczyk M, Stawny M, Wachowski L. Thermal study of four irradiated imidazoline derivatives in solid state. $\mathrm{J}$ Therm Anal Cal. 2007;88:337-42.

16. Ogrodowczyk M, Marciniec B, Hofman M, Naskrent M, Kierzkowska A. Influence of e-beam irradiation on sulfamethoxazole in solid state. Anal Sci. 2011;27:203-8.

17. Marciniec B, Stawny M, Kozak M, Naskrent M. The influence of radiation sterilization on thiamphenicol. Spectrochim Acta Part A. 2008;69:865-70.

18. Dettlaff K, Tężyk A, Marciniec B, Wachowiak R, Naskrent M, Bednarek B. Radiation sterilization of ephedrine in the solid state. Chem Anal. 2008;53:171-86.

19. Edwards HGM, Lawson E, de Matas M, Shields L, York P. Metamorphosis of caffeine hydrate and anhydrous caffeine. J Chem Soc Perkin Trans 2. 1997;10:1985-90.

20. Basly JP, Duroux JL, Bernard M. Gamma irradiation sterilization of orciprenaline and fenoterol. Int J Pharm. 1996;142:125-8.

21. Raffi J, Gelly S, Piccerelle P, Prinderre P, Chamayou A, Baron M. Electron spin resonance: thermoluminescence studies on irradiated drugs and excipients. Radiat Phys Chem. 2002;63:705-7.

22. Marciniec B, Kozak M, Ogrodowczyk M. DSC study of radiostability of 1,4-dihydropyridine derivatives. J Therm Anal Calorim. 2004;77:581-96.

23. Katušin-Ražem B, Hamitouche K, Maltar-Strmečki N, Kos K, Pucić I, Britvić-Budicin S, Ražem D. Radiation sterilization of ketoprofen. Radiat Phys Chem. 2005;73:111-6.

24. Maquille A, Slegers C, Habib Jiwanand JL, Tilquin B. Electronbeam and gamma radiolysis of solid-state metoclopramide. Pharm Res. 2006;23:1343-9.

25. Pronce T, Tilquin B. Radiosterilisation et radioracemisation. J Chim Phys. 1997;94:390-4.

26. Kane MP, Tsuji K. Radiolytic degradation schemes for Co-60 irradiated corticosteroids. J Pharm Sci Technol. 1982;37:51-4.

27. Zeegers F, Gibella M, Tilquin B. Analysis of some products from the irradiation of solid chloramphenicol. Radiat Phys Chem. 1997;50:149-53.

28. Miyazaki T, Kaneko T, Yoshimura T, Crucq AS, Tilquin B. Electron spin resonance study of radiosterilization of antibiotics: ceftazidime. J Pharm Sci. 1994;83:68-71. 